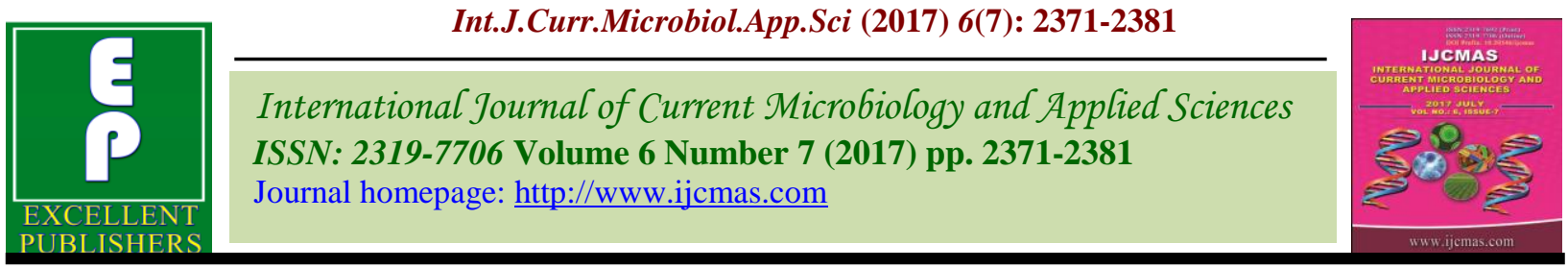

Original Research Article

https://doi.org/10.20546/ijcmas.2017.607.281

\title{
Morphological Characterization and Assessment of Genetic Diversity in Soybean [Glycine max (L.) Merrill] Genotypes
}

\author{
Ravindra Kumar Jain*, Arunabh Joshi and Devendra Jain
}

Department of Molecular Biology and Biotechnology, Rajasthan College of Agriculture, Maharana Pratap University of Agriculture and Technology, Udaipur 313001, Rajasthan, India

*Corresponding author

\section{A B S T R A C T}

Keywords

Soybean, Genetic divergence,

Analysis of

variance, D2

analysis, Cluster

analysis, Inter and

intra-cluster

distance.

Article Info

Accepted:

23 June 2017

Available Online:

10 July 2017
Soybean [Glycine max (L.) Merrill] is a major oil seed crop having 20\% oil and 38 to $43 \%$ protein which has biological value as meat and fish protein. A field experiment was conducted during Kharif 2013 at Agriculture Research Station (ARS), Kota Agriculture University, Kota (Rajasthan) to study the genetic divergence in 24 soybean genotypes and observations on 9 traits of were recorded. The analysis of variance indicated that significant variation was present among the different genotypes of the soybean for all the traits under study. Genetic divergence assessed using $\mathrm{D}^{2}$ statistics for characters enabled grouping of all the genotypes in five clusters. Cluster III was the largest contained 11 genotypes (46 $\%$ ) followed by cluster IV which possessed 7 genotypes. The cluster I, V and II possessed 3, 2 and 1 genotypes, respectively. The cluster III exhibited maximum intra-cluster distance (102.34) while maximum inter-cluster distance was noted between cluster II and III (48.93). Cluster analysis grouped the genotypes into two clusters, cluster I and II that were apart at 25 rescaled values.

\section{Introduction}

Soybean [Glycine max (L.) Merrill] is a major oil seed crop in the world and is called as a golden bean or miracle bean because of its versatile nutritional qualities having $20 \%$ oil and 38 to 43 percent protein, which has biological value as meat and fish protein and rich in amino acids like lysine and tryptophan (Quayam et al., 1985). In the international world trade, soybean is ranked number one among the major oil crops such as rapeseed, groundnut, cottonseed, sunflower, linseed, sesame and safflower (Chung and Singh, 2008). Soybean builds up the soil fertility by fixing large amounts of atmospheric nitrogen through the root nodules, and also through leaf fall on the ground at maturity. It has a fairly wide range of adaptation involving a wide array of climatic, soil and growth conditions and known for its highly valued protein and oil owing to its use in food, feed and industrial applications (Kumar et al., 2015). Soybean being the richest, cheapest and easiest source of best quality proteins and fats and having a vast multiplicity of uses as food and industrial products is sometimes called a wonder crop (Gopinath et al., 2015). Unlike most of the vegetable proteins, soybean protein supplies all the essential 
amino acids, having cardio friendly oil which fulfills 30 percent of world vegetable oil requirement and also has many therapeutic components, namely, lactose-free fatty acids, antioxidants and folic acid, vitamin B complex, and isoflavones (Mathur, 2004).

The assessment of available genetic variability is of utmost importance in all the crop improvement programmes. This is important for several reasons: the ability to distinguish reliably different genotypes is important for designing the breeding programmes, population-genetic analysis, genetic engineering and an estimation of the amount of variation within genotypes and between genotypes is useful for predicting potential genetic gains in a breeding programme and in setting up appropriate cross-breeding strategies (Bhakuni et al., 2017). Genetic variability is the basic requirement for crop improvement as this provides wider scope for selection. Knowledge of diversity patterns will allow breeders to better understand the evolutionary relationships among accessions, to sample germplasm in a more systematic fashion and to develop strategies to incorporate useful diversity in their breeding programs (Naik et al., 2016).

Genetic relationships among number of tested genotypes can be measured by similarity using number of quantitative characters which meaning that the differences among characters of tested genotypes attributed to the genetic divergence of these genotypes in soybean (Iqbal et al., 2008; Ojo et al., 2012). Several methods including Morphological and agronomic traits have been used to investigate the genetic variation in soybean (Perry and McIntosh, 1991; Sneller et al., 1997). For yield improvement, it is essential to have knowledge on the variability of different characters such as days to $50 \%$ flowering, days to maturity, plant height $(\mathrm{cm})$, number of branches/plant, number of pods/plant, number of seeds/plant, 1000-seed weight (g), seed yield per plant $(\mathrm{g})$, biological yield $(\mathrm{g})$, and harvest index (\%). Morphological traits can be used to assess phenotypic variation in growing environments and are also used as tools for the indirect analysis of genetic variability and diversity (Kaur et al., 2016). As in other major crops, genetic diversity of soybean grown is very narrow (BrownGuedira et al., 2000) and has been confirmed in many studies based on pedigree analysis (Delannay et al., 1983; Gizlice et al., 1994) or molecular markers (Narvel et al., 2000; Thompson et al., 1998; Khatab and Morsy, 2012).

The information on genetic diversity helps in choosing parents for generation of new varieties, needs of continuous evaluation of germplasm for useful characters, which in earlier days was solely based on the available morphological data. Morphological traits/markers reflect not only on the genetic composition of the cultivar, but also the interaction of the genotype with the environment in which it is expressed (Shadakshari et al., 2011).

The main objective of this study was to characterize soybean genotypes using morphological markers in order to evaluate the genetic diversity and relationships among selected genotypes.

\section{Materials and Methods}

The present study was conducted at Agriculture Research Station (ARS), Kota Agriculture University, Kota (Rajasthan) and Department of Molecular Biology and Biotechnology, Rajasthan College of Agriculture, MPUAT, Udaipur (Rajasthan) to analyze the genetic among soybean genotypes diversity during Kharif, 2013. Twenty four genotypes of soybean were procured from 
ARS, Kota. Source and pedigree of the material are given in table 1 .

The field experiment was laid out in randomized block design (RBD) with three replications. Twenty four genotypes were planted with a spacing of $30 \mathrm{~cm}$ row to row and $10 \mathrm{~cm}$ plant to plant distance. Fertilizers

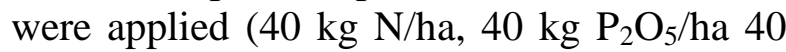
$\mathrm{kg} \mathrm{K}_{2} \mathrm{O} / \mathrm{ha}$ and $30 \mathrm{~kg} \mathrm{~S} / \mathrm{ha}$ ) at the time of sowing. All the recommended agronomical practices and plant protection measures were adopted to raise the healthy crop.

At maturity five competitive plants were randomly selected from each replication of each genotype to recorded observation, except for days to 50 per cent flowering and days to maturity observation recorded on plot basis. The procedure adopted for recorded observations / data on different characters are as follow: Plant height $(\mathrm{cm})$, Days to 50 per cent flowering, Days to maturity, Number of branches per plant, Number of pods per plant, Number of seeds per pod, Seed yield per plant (g), Test weight (g) and Harvest index (\%).

The data on morphological traits of three replication was subjected to analysis of variance on the basis of model described by Panse and Sukhatme (1985) for individual characters. The replicated data were subjected to genetic divergence analysis using Mahalanobis's $D^{2}-$ statistic (Mahalanobis 1936). For the present investigation based on morphological and quality characters data, grouping of 24 genotypes of soybean was done using Ward's minimum variance method. Intra and inter-cluster distances generated were used to describe the relationship among the genotypes.

\section{Results and Discussion}

In the present investigation, 9 important morphological and quality characters have been studied to evaluate the pattern and extent of genetic variability and relatedness among 24 genotypes of G. $\max$ L. The average mean squares from the ANOVA for different characters (Table 2) revealed that the mean squares due to genotypes were highly significant for all the characters. This indicates the presence of significant genetic variability in the material which provides scope for selection and further subsequent utility of the genotypes in the crop improvement programme. Similarly, Iqbal et al., (2008) and Tantasawat et al., (2010) revealed significant differences among different soybean genotypes for all the traits studied.

The genetic divergence analysis was done for all the nine characters and the hierarchical cluster analysis of 24 genotypes yielded five clusters at 100 Mahalnobis Euclidean ${ }^{2}$ Distance as per Ward's minimum variance dendrogram with variable number of genotypes is presented in table 3 . The data indicates presence of considerable amount of genetic diversity amongst the genotypes.

It has been found that Cluster III was the largest comprising about 11 genotypes or $46 \%$ of the genotypes belonged to this cluster followed by cluster IV that consist 7 genotypes. The cluster I, V and II possessed 3,2 and 1genotypes respectively (Table 3).

The intra- and inter-cluster distances values between 5 clusters are presented in table 4 and also Euclidean ${ }^{2}$ Distance in figure 1 . The perusal of mean in table 4 revealed that intracluster distances were greater than intercluster distances, revealing considerable amount of genetic diversity among the genotypes studied. Genotypes belonging to clusters with maximum intra-cluster distance are genetically more divergent and hybridization between divergent clusters is likely to produce wide variability with 
desirable segregant (Maloo and Bhattacharjee, 1999). The average intra-cluster distance between the genotypes was maximum for the cluster III (102.34) followed in descending order by cluster IV (66.07), I (33.71) and V (12.83) respectively.

The highest inter-cluster distance was noted between cluster II and III (48.93) followed by cluster II and V (46.90), II and IV (42.49), I and II (31.65) and so on. The genotypes grouped in these clusters indicated them to be of diverse nature. The least (14.05) intercluster distance was observed for cluster III and $\mathrm{V}$ indicated their genetic relatedness.

The cluster mean and general mean values for 9 characters of 24 G. max L. genotypes have been presented in table 5 . The perusal of the mean data revealed that differences in cluster means had existed. Cluster I comprised of three genotypes which were characterized as having above average values for days to maturity, days to $50 \%$ flowering, number of pods per plant, test weight and seed yield per plant. Cluster II had one genotype that indicated the above average values for all the characters studied except for number of branches per plant and number of pods per plant. Cluster III comprised of 11 genotypes which was characterized as having above average value for days to maturity, days to $50 \%$ flowering and number of seeds per pod. Cluster IV involving 7 genotypes was characterized as having above average value for all the characters studied except for test weight. Cluster V consisted of 2 genotypes indicated none of the above average value for any of the characters studied except number of branches per plant, number of seeds per pod.

Fig.1 Intra and inter-cluster distance for 24 genotypes of Glycine max L.

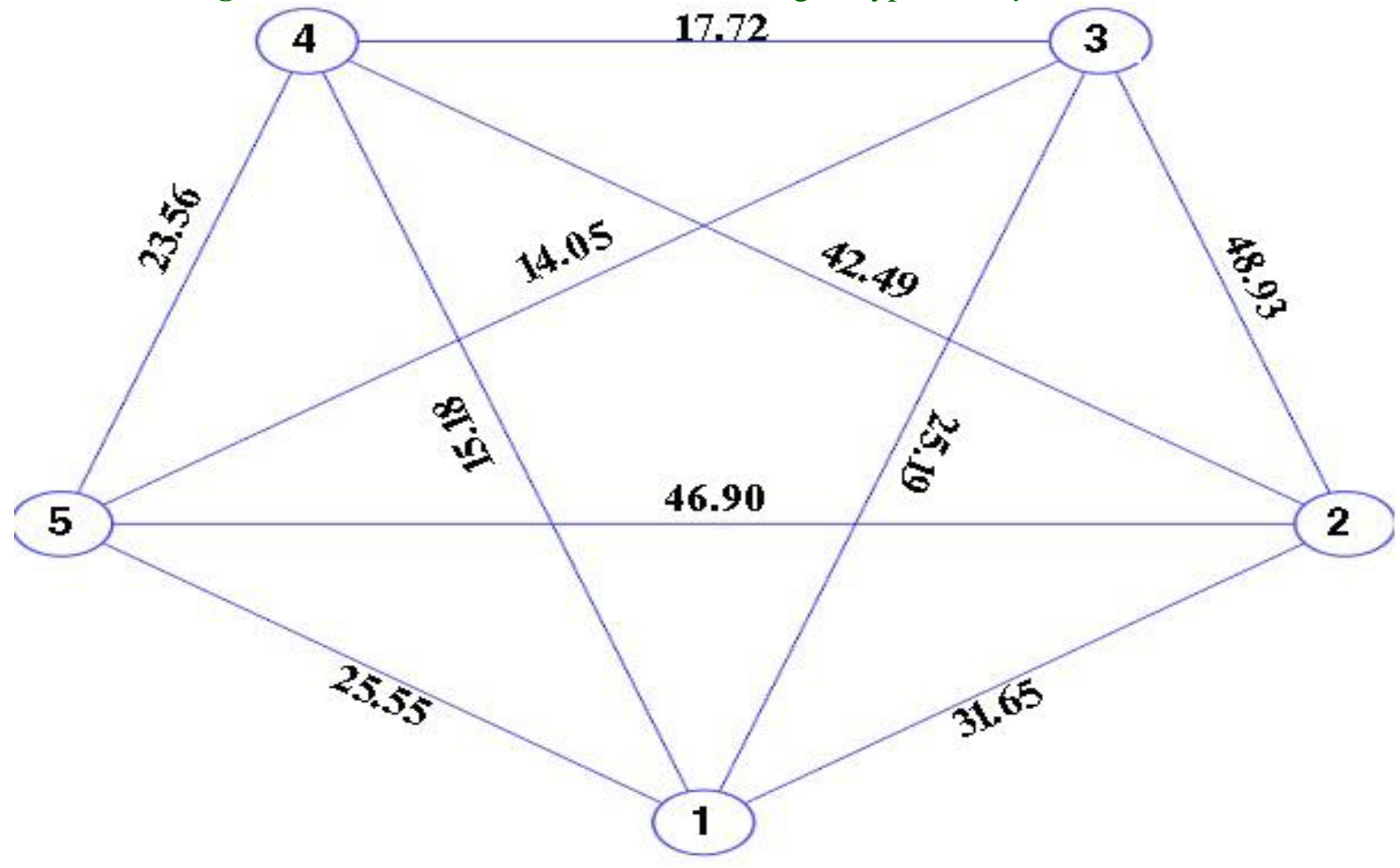

Euclidean ${ }^{2}$ Distance (Not to the Scale) 
Fig.2 Ward's Minimum Variance Dandrogram for 24 genotypes of Glycine max L.

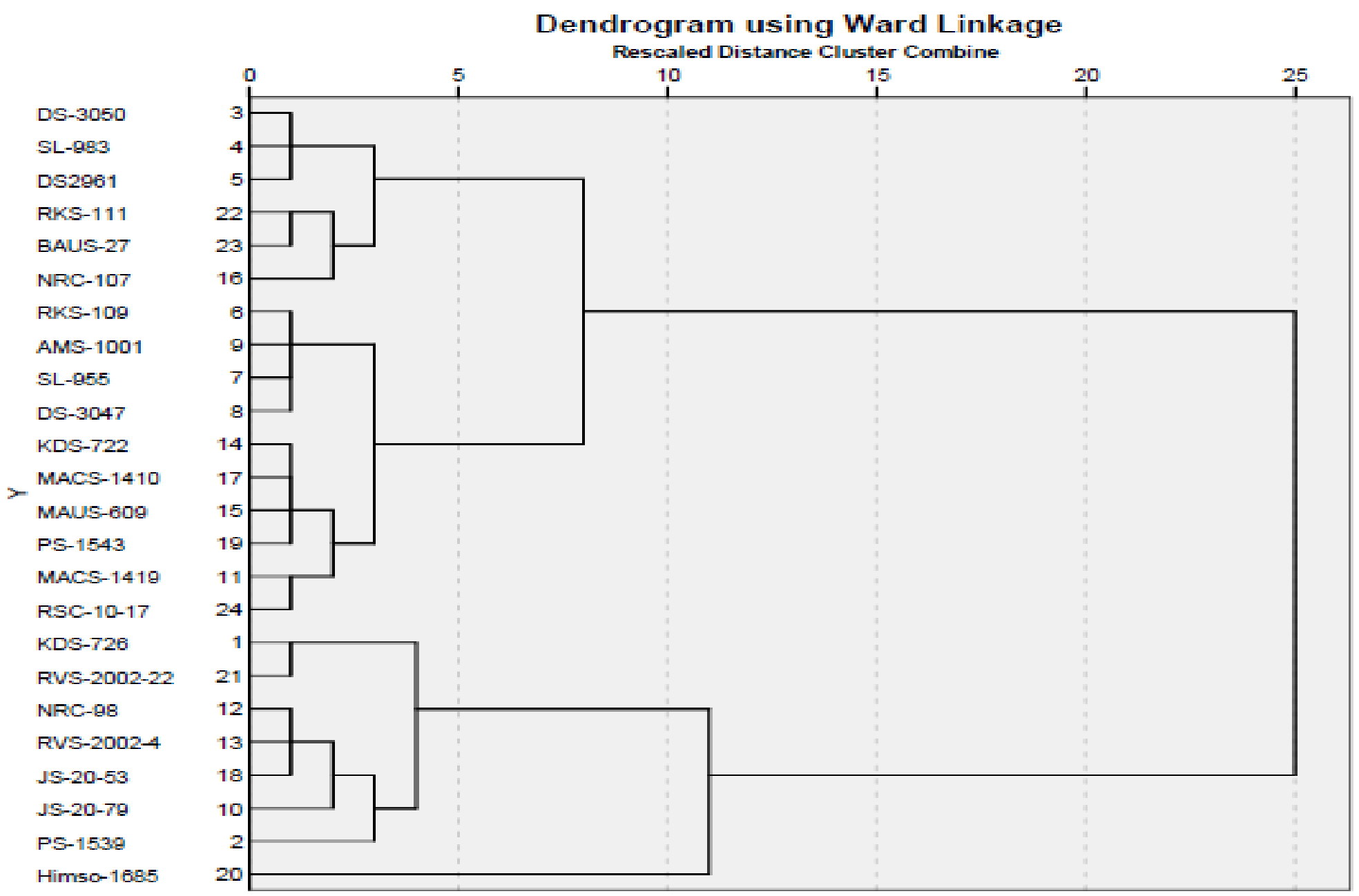


Table.1 Pedigree and source of 24 genotypes of Glycine max L. Merrill

\begin{tabular}{|c|c|c|c|}
\hline S.No. & Genotypes & Pedigree & Source \\
\hline 1. & KDS-726 & JS-93-05 X EC-241780 & SANGLI (MH) \\
\hline 2. & PS-1539 & PS-1024 X JS-335 & PANTNAGAR \\
\hline 3. & DS-3050 & DT-23 X DT-227 & DELHI \\
\hline 4. & SL-983 & SL-525 X PK-1368 & LUDHIANA \\
\hline 5. & DS-2961 & MO-74 X JS-335 & DELHI \\
\hline 6. & RKS-109 & RKS-224 X PK-1024 & KOTA \\
\hline 7. & SL-955 & SL-599 X PK-1283 & LUDHIANA \\
\hline 8. & DS-3047 & DT-23 X DT-27 & DELHI \\
\hline 9. & AMS-1001 & Mutant of JS-93-05 & AMARAWATI \\
\hline 10. & JS-20-79 & JS-97-52 X JS-(15) 90-5-12-1 & JABALPUR \\
\hline 11. & MACS-1419 & EC-391343 X MACS-450 & PUNE \\
\hline 12. & NRC-98 & Ankur X PK-1024 & INDORE \\
\hline 13. & RVS-2002-4 & JP-120 X JS-335 & SIHORE \\
\hline 14. & KDS-722 & AMS-99 X EC-241780 & SANGLI (MH) \\
\hline 15. & MAUS-609 & Himso-1563 X MAUS-71 & PARBANI \\
\hline 16. & NRC-107 & Mutant of NRC-37 & INDORE \\
\hline 17. & MACS-1410 & MAUS-144 X MACS-450 & PUNE \\
\hline 18. & JS-20-53 & JS-97-52 X JS-20-02 & JABALPUR \\
\hline 19. & PS-1543 & PS-1029 X JS-335 X PS-1241 & PANTNAGAR \\
\hline 20. & Himso-1685 & H-330 X HARDEE & PALAMPUR \\
\hline 21. & RVS-2002-22 & NRC-37 X JS-39-05 & SIHORE \\
\hline 22. & RKS-111 & RKS-45 X RKS-24 & KOTA \\
\hline 23. & BAUS-27 & PK-472 X L-119 & RANCHI \\
\hline 24. & RSC-10-17 & MAUS-144 X RAUS-5 & RAIPUR \\
\hline
\end{tabular}


Table.2 ANOVA for the 9 choosen characters in 24 genotypes of Soybean

\begin{tabular}{|c|c|c|c|c|}
\hline \multirow{2}{*}{ S. } & \multirow{2}{*}{ Cho. } & \multicolumn{3}{|c|}{ Source of variation } \\
\cline { 2 - 5 } & & Replications & Treatments & Error \\
\cline { 2 - 5 } & degree of freedom (df) & $\mathbf{( 2 )}$ & $\mathbf{( 2 3 )}$ & $\mathbf{( 4 6 )}$ \\
\hline \multirow{1}{*}{ 2. } & Days to maturity & 24.0139 & $57.903 * *$ & 9.0284 \\
\hline 3. & Days to 50\% flowering & 8.7917 & $27.080^{* *}$ & 3.2409 \\
\hline 4. & Plant height (cm) & 20.3937 & $69.148^{* *}$ & 13.2271 \\
\hline 5. & No. of branches/plant & 0.0865 & $1.353^{* *}$ & 0.1355 \\
\hline 6. & No. of pods/plant & 57.5417 & $217.652^{* *}$ & 22.8460 \\
\hline 7. & No. of seeds/pod & 0.0203 & $0.193^{* *}$ & 0.0491 \\
\hline 8. & Test weight (g) & 24.2739 & $337.859^{* *}$ & 25.7633 \\
\hline 9. & Seed yield /plant (g) & 2.1022 & $45.292^{* *}$ & 3.2429 \\
\hline
\end{tabular}

* Significant at 5 per cent and **Significant at 1 per cent probability level

Table.3 Cluster profile of 24 genotypes of Glycine max L.

\begin{tabular}{|c|c|l|}
\hline Cluster & $\begin{array}{c}\text { No. of } \\
\text { genotypes }\end{array}$ & \multicolumn{1}{|c|}{ Genotype Name } \\
\hline I & 3 & KDS-726, PS-1539 and RVS-2002-22 \\
\hline II & 1 & Himso-1685 \\
\hline III & 11 & $\begin{array}{l}\text { DS-3050, SL-983, DS-2961, RKS-109, DS-3047, MACS-1419, KDS- } \\
722, \text { MAUS-609, MACS-1410, BAUS-27 and RSC-10-17 }\end{array}$ \\
\hline IV & 7 & $\begin{array}{l}\text { SL-955, AMS-1001, JS-20-79, NRC-98, RVS-2002-4, JS-20-53 and } \\
\text { PS-1543 }\end{array}$ \\
\hline V & 2 & NRC-107 and RKS-111 \\
\hline
\end{tabular}

Table.4 Estimates of intra- (diagonal) and inter-cluster distances in 24 genotypes of Glycine max L.

\begin{tabular}{|c|c|c|c|c|c|}
\hline Cluster & I & II & III & IV & V \\
\hline I & $\mathbf{3 3 . 7 1}$ & 31.65 & 25.18 & 15.18 & 25.55 \\
\hline II & & $\mathbf{0 . 0 0}$ & 48.93 & 42.49 & 46.90 \\
\hline III & & & $\mathbf{1 0 2 . 3 4}$ & 17.72 & 14.05 \\
\hline IV & & & & $\mathbf{6 6 . 0 7}$ & 23.56 \\
\hline V & & & & & $\mathbf{1 2 . 8 3}$ \\
\hline
\end{tabular}


Table.5 Cluster means and average (overall) values for various characters in 24 genotypes in Glycine max L.

\begin{tabular}{|c|c|c|c|c|c|c|c|c|c|c|}
\hline Cluster & $\begin{array}{c}\text { Number } \\
\text { of } \\
\text { Genotypes }\end{array}$ & $\begin{array}{l}\text { Days to } \\
\text { maturity } \\
\text { (Days) }\end{array}$ & $\begin{array}{l}\text { Days to } \\
50 \% \\
\text { flowering } \\
\text { (Days) } \\
\end{array}$ & $\begin{array}{c}\text { Plant } \\
\text { height } \\
(\mathrm{cm})\end{array}$ & $\begin{array}{l}\text { Number } \\
\text { of } \\
\text { Branches } \\
\text { /plant } \\
\end{array}$ & $\begin{array}{l}\text { Number } \\
\text { of Pods } \\
\text { /plant }\end{array}$ & $\begin{array}{l}\text { Number } \\
\text { of seeds } \\
\text { /pod }\end{array}$ & $\begin{array}{c}\text { Test } \\
\text { weight } \\
\text { (g) }\end{array}$ & $\begin{array}{l}\text { Seed } \\
\text { yield } \\
\text { /plant } \\
(\mathrm{g}) \\
\end{array}$ & $\begin{array}{c}\text { Harvest } \\
\text { index } \\
(\%)\end{array}$ \\
\hline $\mathbf{I}$ & 3 & 41.11 & 98.00 & 47.50 & 7.00 & 80.89 & 2.56 & 119.1 & 24.80 & 45.03 \\
\hline II & 1 & 40.67 & 101.67 & 53.19 & 7.00 & 69.33 & 3.00 & 143.7 & 30.08 & 58.28 \\
\hline III & 11 & 42.15 & 99.15 & 48.94 & 6.64 & 66.27 & 2.97 & 100.9 & 19.84 & 37.88 \\
\hline IV & 7 & 41.57 & 98.14 & 53.50 & 7.10 & 79.43 & 3.05 & 105.3 & 25.43 & 45.15 \\
\hline $\mathbf{V}$ & 2 & 35.67 & 90.66 & 42.01 & 7.33 & 63.50 & 3.00 & 105.9 & 20.44 & 38.96 \\
\hline Mean & 4.8 & 40.23 & 97.52 & 49.02 & 7.01 & 71.88 & 2.91 & 114.98 & 24.11 & 45.06 \\
\hline \multicolumn{2}{|c|}{ Treatment MSS } & 57.90 & 27.08 & 69.14 & 1.35 & 217.65 & 0.19 & 337.85 & 45.29 & 118.28 \\
\hline \multicolumn{2}{|c|}{ Err MSS } & 9.02 & 3.24 & 13.22 & 0.13 & 22.84 & 0.04 & 25.76 & 3.24 & 14.55 \\
\hline \multicolumn{2}{|c|}{ F Ratio } & 6.41 & 8.35 & 5.22 & 10.38 & 9.52 & 4.75 & 13.11 & 13.97 & 8.12 \\
\hline \multicolumn{2}{|c|}{$\begin{array}{l}\text { Percent contribution } \\
\text { towards variability }\end{array}$} & 0.074 & 0.123 & 0.012 & 0.561 & 0.000 & 0.058 & 0.000 & 0.001 & 0.001 \\
\hline
\end{tabular}


Ward's hierarchical cluster analysis was carried out on the basis of 9 morphological characters, used to measure genetic distance between the 24 G. max L. genotypes (Fig. 2). Cluster analysis grouped the genotypes into two clusters, cluster I and II that were apart at 25 rescaled values.

Cluster I included 16 genotypes viz., DS3050, SL-983, DS-2961, RKS-111, BAUS27, NRC-107, RKS-109, AMS-1001, SL-955, DS-3047, KDS-722, MACS-1410, MAUS609, PS-1543, MACS-1419 and RSC-10-17. It could further be divided into 2 sub clusters at 8 rescaled distances. Sub cluster I included 6 genotypes viz., DS-3050, SL-983, DS-2961, RKS-111, BAUS-27 and NRC-107. It could be further sub grouped into 2 subgroups at 3 rescaled distance. Subgroup A consisted of 3 genotypes viz., DS-3050, SL-983 and DS2961which were 1 rescaled distance apart from each other. Subgroup B consisted of 3 genotypes viz., RKS-111, BAUS-27 and NRC-107 which was 3 rescaled distance apart from each other. Sub cluster II included 10 genotypes viz., RKS-109, AMS-1001, SL955, DS-3047, KDS-722, MACS-1410, MAUS-609, PS-1543, MACS-1419 and RSC10-17. It also could be further sub grouped into 2 subgroups at 3 rescaled distance.

Subgroup A consisted of 4 genotypes viz., RKS-109, AMS-1001, SL-955 and DS-3047 which were 1 rescaled distance apart from each other. Subgroup B consisted of 6 genotypes viz., KDS-722, MACS-1410, MAUS-609, PS-1543, MACS-1419 and RSC10-17. It can be again subdivided into two sub cluster at 2 rescale distances. First sub cluster consisted of 4 genotypes viz., KDS-722, MACS-1410, MAUS-609 and PS-1543 which were 1 rescaled distance apart from each other. The second one consisted of two genotypes viz., MACS-1419 and RSC-10-17 which also were 1 rescaled distance apart from each other.
Cluster II included 8 genotypes viz., KDS726, RVS-2002-22, NRC-98, RVS-2002-4, JS-20-53, JS-20-79, PS-1539 and Himso1685. Cluster II consist a sub cluster which included 7 genotypes viz., KDS-726, RVS2002-22, NRC-98, RVS-2002-4, JS-20-53, JS-20-79 and PS-1539.

This sub cluster could be further sub grouped into 2 subgroups at 4 rescaled distance. Subgroup A consisted of 2 genotypes viz., KDS-726and RVS-2002-22 which were 1 rescaled distance apart from each other. Subgroup B consisted of 5 genotypes viz., NRC-98, RVS-2002-4, JS-20-53, JS-20-79 and PS-1539. This subgroup B consist a single subgroup which also consisted a single subgroup included three genotypes viz., NRC98, RVS02002-4 and JS-20-53which were 1 rescaled distance apart from each other.

Result revealed that intra-cluster distances were greater than inter-cluster distances, revealing considerable amount of genetic diversity among the genotypes studied. Genotypes belonging to clusters with maximum intra-cluster distance are genetically more divergent and hybridization between divergent clusters is likely to produce wide variability with desirable segregant (Maloo and Bhattacharjee, 1999). The ANOVA of morphological data revealed that mean squares for all genotypes were significant for all the characters.

This finding will be helpful to plant breeders for characterization, identification, selection and authentication of genotypes of soybean for future crop improvement programmes.

The results of the present study could also be used as a stepping stone for evolving a welldefined approach based on evaluation and characterization of genetic variation in selected soybean genotypes. 


\section{Acknowledgement}

Authors gratefully acknowledge Dr. H. R. Chaudhary and Dr. Abhay Dashora ARS Kota, Agriculture University, Kota for providing seed material and necessary support.

\section{References}

Bhakuni, V., Shukla, P.S., Singh, K. and Singh, V.K. 2017. Morphological Characterization and Assessment of Genetic Variability in Soybean Varieties. International Journal of Current Microbiology and Applied Sciences, 6(3): 361-369.

Brown-Guedira, G. L., Thompson, J. A., Nelson, R. L. and Warburton, M. L. 2000. Evaluation of genetic diversity of soybean introductions and North American ancestors using RAPD and SSR markers. Crop Science, 40(3): 815823.

Chung, G. and Singh, R.J. 2008. Broadening the Genetic Base of Soybean: A Multidisciplinary Approach. Critical Review in Plant Sciences, 27: 295-341.

Delannay, X., Rogers, D.M. and Palmer, R.G. 1983. Relative genetic contributions among ancestral lines to North American soy- bean cultivars. Crop Science, 23: 944-949.

Gizlice, Z., Carter, T.E. and Burton, J.W. 1994. Genetic base for North American public soybean cultivars released between 1947 and 1988. Crop Science, 34:1143-1151.

Gopinath, P. and Pavadai, P. 2015. Morphology and Yield parameters and Biochemical analysis of Soybean (Glycine max (L.) Mrr.) Using Gamma rays, EMS and DES treatment. International Letters of Natural Sciences, 35: 50-58.

Iqbal, Z., Arshad, M., Ashraf, M., Mahmood,
T. and Waheed, A. 2008. Evaluation of soybean [Glycine max (L.) Merr.] germplasm for some important morphological traits using multivariate analysis. Pakistan Journal of Botany, 40(6): 2323- 2328.

Kaur, G., Joshi, A., Jain, D. Choudhary, R. and Vyas, D. 2016. Diversity analysis of green gram (Vigna radiata (L.) Wilczek) through morphological and molecular markers. Turkish Journal of Agriculture and Forestry, 40: 229-240.

Khatab, A.I. and El-Banna, A.N. 2014. Establishment of a high efficiency Agrobacterium- mediated transformation conditions of soybean callus. Indian Journal of biotechnology, 13: 459-463.

Kumar, A., Pandey, A. and Pattanayak, A. 2015. Assessment of genotypic variation in soybean (Glycine max). Legume Research, 38(2): 174-177.

Mahalanobis, P.C. 1936. On the generalized distances in statistics. Proceedings of National Institute of Sciences of India, 2: 49-55.

Maloo, S. R. and Bhattacharjee, I. 1999. Genetic divergence in foxtail millet. Recent advances in management of arid ecosystem proceedings of a symposium held in India. March, 1997, pp. 155158.

Mathur, S. 2004. Soybean: The wonder legume. Beverage and Food world. January, 2004.

Naik, S.M., Madhusudan, K., Motagi1, B.N. and Nadaf, H.L. 2016. Diversity in Soybean (Glycine max) Accessions Based on Morphological Characterization and Seed Longevity Characteristics. Thimmarajul Progressive Research - An International Journal, 11(3): 377-381.

Narvel, J.M., Fehr, W.R., Chu, W., Grant, D. and Shoemaker, R.C. 2000. Simple sequence repeats diversity among 
soybean plant introductions and elite genotypes. Crop Science, 40: 14521458.

Ojo, D.K., Ajayi, A.O. and Oduwaye, O.A. 2012. Genetic relationships among soybean Accessions based on morphological and RAPDS Techniques. Pertanika J. Trop. Agric. Sci., 35(2): 237-248.

Panse, V.G., and Sukhatme, P.V. 1985. Statistical Methods for Agricultural Research Workers. Indian Council of Agricultural Research, New Delhi.

Perry, M.C. and McIntosh, M.S. 1991. Geographical patterns of variation in USDA soybean germplasm collection: I. Morphological traits. Crop Science, 31: 1350-1355.

Quayam, A., Rao, M.S.S. and Kerketta, V. 1985. Soybean: A miracle oil seed cropits prospects and constraints in Bihar plateau. In proceedings of Oil Seed Production Constraints and Opportunities, pp: 219-232.

Shadakshari, T.V., Kalaimagal, T., Senthil, N., Boranayaka, M.B., Kambe Gowda,
R. and Rajesha, G. 2011. Genetic diversity studies in soybean [Glycine $\max$ (L.) Merrill] based on morphological characters. Asian Journal of Bio Science, 6(1): 7-11.

Sneller, C.H., Miles, J.W and Hoyt, J.M. 1997. Agronomic performance of soybean plant introductions and their similarity to elite lines. Crop Science, 37: 1595-1600.

Tantasawat, P., Trongchuen, J., Prajongjai, T., Jenweerawat, S. and Chaowiset, W. 2011. SSR analysis of soybean (Glycine $\max (\mathrm{L}$.) Merr.) Genetic relationship and variety identification in Thailand. Australian Journal of Crop Science, 5: 283-290.

Thompson, J.A., Nelson, R.L. and Vodkin, L.O. 1998. Identification of diverse soybean germplasm using RAPD markers. Crop Science, 38: 1348-1355.

Ward, J.H. 1963. Hierarchical grouping to optimize an objective function. Journal American Statistics Association, 58: 236-244.

\section{How to cite this article:}

Ravindra Kumar Jain, Arunabh Joshi and Devendra Jain. 2017. Morphological Characterization and Assessment of Genetic Diversity in Soybean [Glycine max (L.) Merrill] Genotypes. Int.J.Curr.Microbiol.App.Sci. 6(7): 2371-2381. doi: https://doi.org/10.20546/ijcmas.2017.607.281 